\title{
LA ESCRITURA DE BARCELONA EN LA OBRA DE MANUEL VÁZQUEZ MONTALBÁN: ENTRE RUPTURA Y PERSONIFICACIÓN
}

\author{
THE ECRITURE OF BARCELONA IN THE WORK OF MANUEL \\ VÁZQUEZ MONTALBÁN: BETWEEN BREAK AND PERSONIFICATION
}

\author{
Arnaud N. Mandy Dibangou \\ Universidad de Perpignan. Perpignan, Francia \\ mandyarnaud@yahoo.fr
}

$\mathrm{D}_{\mathrm{c}}^{\mathrm{s}}$

E ACUERDO CON LOS ESCRITOS de Victor Hugo, Flaubert, Zola, Dickens o

Galdós, el espacio urbano hace sus primeras incursiones en literatura a la vez como personaje y sujeto eminentemente social. Las grandes ciudades aparecen ya como espacios funcionales y contrastados donde las instituciones, la diversidad y los influjos socioeconómicos alimentan un discurso crítico sobre la sociedad en general. La ciudad representa así el pretexto del sujeto socio-literario volviéndose, como lo sugiere Henri Mitterand, un lenguaje, una acción, una función y árbol cuya "corteza” abriga la revelación (1980: 189-212).

Este papel predominante en la narración y en la poesía coincide extraordinariamente con el desarrollo de las ciudades iniciado en el siglo XIX y amplificado en el XX. Un desarrollo que hace de la ciudad un medio móvil donde la inestabilidad y la confluencia son fuentes de angustias y alineación.

En la obra de Manuel Vázquez Montalbán, la ciudad (en particular la de Barcelona) representa la materia principal de la escritura. El escritor recorre esta geometría a veces laberíntica como explorador para destacar los más significantes estratos donde se encuentra la historia de un pueblo, una historia de pulsiones, aspiraciones, frustraciones y violencia.

Nuestro trabajo deberá pues evidenciar la actitud siempre dinámica y novadora del autor en ruptura permanente con las convenciones y los có- 
digos genéricos vigentes. Nuestro enfoque es una forma de paseo para descubrir paulatinamente este espacio aún mal conocido a través de la lectura de obras narrativas y poéticas que tienen una declarada o implícita relación con la ciudad de Barcelona.

\section{Espacio y memoria}

La Barcelona del autor es ante todo una ciudad compuesta por fracturas y fronteras cuyas distorsiones y contrastes aparecen casi siempre en la voz de los personajes. Se trata de una ciudad de referencia de la que el locutor poético de "Pero el viajero que huye" no puede deshacerse (Vázquez Montalbán, 2001a: 6):
Viajaras conmigo hasta mi muerte rota rosa de abril ensimismada entre las páginas de cuanto he escrito.

Pero es también la Barcelona de una memoria "posesiva y hegemónica" que resiste al compromiso del olvido para restablecer la historia de una vida. Por otra parte, Montalbán subraya en una entrevista a Quim Aranda en lengua catalana: "el meu tipus d'escritura es fonamenta mes aviat en experiencies de la memoria effets vivencials" (Aranda, 1995: 20).

Esta indivisibilidad de la memoria y de la vida muy presente en su producción literaria transcribe una doble impulsión a la vez individual y colectiva. La de un humanista investido del deber y de la responsabilidad de hacerse el portavoz de los habitantes de Raval, su ciudad natal. De este compromiso nace una forma de realismo crítico que el autor define en estos términos:

En la construcción de la ciudad democrática, arte y letras se aplican a dos objetivos fundamentales: la recuperación de la memoria del vencido y la descripción de la realidad en clave no triunfalista en busca de un nuevo lenguaje solidario y por lo tanto comunicativo y crítico (Montalbán, 2001b:63).

Dichos objetivos fundamentales aparecen con insistencia en La literatura en la construcción de la ciudad democrática. Esta obra que es en 
realidad una forma de auto-análisis presenta además unos elementos de reflexión sobre la acción de escribir, una experiencia del mundo y un saber metamorfoseado en discurso gracias en parte a la memoria:

Funciona una relación constante pero subconsciente entre lo que sabes sobre escribir y la escritura de cara a conseguir un verosímil literario. En poesía, novela y ensayo lo verosímil a diferencia del cine o teatro, sólo puede conseguirse mediante palabras (Vázquez Montalbán, 2001b: 65).

Podemos relacionar esta visión con la famosa afirmación de Jean Yves Tadié: "Pour un écrivain la transcendance de l'espace ne peut être que le langage, l'essence sous l'apparence est faite de mots" (1994: 76).

\section{Entre palabras e imaginario}

La palabra como instrumento de transcripción de la historia tiene también una función terapéutica desde un punto de vista individual, ya que permite al autor domesticar sus propias angustias frente a la vulnerabilidad de la existencia. Por eso Vázquez Montalbán afirma:

De pocas cosas podemos sentirnos orgullosos, pero una de ellas es la de haber inventado el truco de liberarnos del miedo a los otros y a las cosas poniéndoles nombres, de liberarnos del miedo a la relación tiempoespacio inventando las líneas imaginarias y la toponimia y de liberarnos también del miedo al tiempo encerrándolo en el laberinto de los calendarios (Vázquez Montalbán, 1997: 219).

En estas condiciones, la labor del escritor consiste también en evidenciar el imaginario del habitante de la ciudad, ya que no existe otra manera de examinar la realidad sino a través del imaginario. Así la ciudad de Barcelona a la vez realidad y representación, lugar de elección o de adopción "forjando" la naturaleza del ser vivo, suscita intentos de apropiación con las palabras que van desde la simple enunciación hasta la interpretación simbólica.

Dichas palabras tienen también, además de una simple reproducción, el poder de producir una realidad. En una entrevista a Quim Aranda, el 
autor define las relaciones entre el escritor y la realidad. Sostiene inequívocamente que cuando uno escribe, manifiesta de golpe su odio a la realidad. Intenta pues construir otra tan fugaz e inconstante como lo puede ser una realidad fundamentada en las palabras. Para Manuel Vázquez Montalbán, se trata de una forma de reconciliación de la memoria y el deseo.

Ya se puede ver que la estrategia del compromiso consiste en corregir los daños del tiempo, del olvido y de la ignorancia transformando la experiencia en discurso:

Sea cuales sean los cambios estructurales, la literatura seguirá teniendo que ubicarse en una tensión dialéctica entre su propio y viejo saber y la relación con la vida y la historia en movimiento. Esclava de la palabra, proyectará esta esclavitud hacia las ideas y la bondad o maldad de esa fatal carga ideológica de lo literario, seguirá dependiendo del artificioso talento del autor aplicado a convertir lo ideológico en lo literario (Tyras, 1985: 219).

Se trata para el autor de conservar y restituir la memoria subjetiva de la historia reciente de Barcelona ampliando el campo de las posibilidades. Montalbán imagina pues una estética en el servicio de la ética con la que se siente encariñado y formula propuestas vanguardistas que integran en la cultura tradicional elementos de la reciente "subcultura" periodística.

Esta orientación estética, aunque firmemente crítica con las opciones literarias de las generaciones anteriores, le permite quedar en consonancia con la realidad del momento sin pretender modificarla.

Preconiza una forma de renovación personal mediante transgresiones sucesivas de los códigos vigentes. Eliot explica que toda aproximación estética concreta es el resultado de un punto de convergencia entre la tradición y la revolución del patrimonio literario.

Este mecanismo de ruptura caracteriza la totalidad de la obra de Vázquez Montalbán. En efecto, es con un principio de ruptura lingüística como el escritor da sus primeros pasos como poeta, ensayista y novelista. De esta ruptura inicial (y casi iniciática) nace una pluralidad de rupturas puntuales ulteriores. Podemos pensar que la trayectoria literaria del autor es semejante a la ciudad donde nació. Parte de un núcleo central, "una escritura inicial”, y se despliega en ámbitos variados sacudiendo las normas vigentes para ajustarse a una realidad particularmente cambiante como Barcelona 
que se edifica una fachada marítima para ofrecer al mundo la imagen de una modernidad.

\section{La ruptura}

La noción de ruptura se integra en un contexto sociopolítico específico a la España postguerrera, bastante cerrada a las influencias extranjeras a causa de la dictadura franquista. Tenemos pues por un lado la represión y el autoritarismo de un sistema comprometido a mantenerse en el poder y por otro el discurso realista que pretende expresar objetivamente la triste realidad del país otorgando a la literatura un poder de intervención en la sociedad.

Así, el escritor de los años 50 nutre la idea de un estatuto profético que parece sobrepasar el carácter ilusorio de su intervención en un mundo donde la literatura ya no desempeña un papel determinante en la formación de la conciencia colectiva (la prensa asumiendo ya el control, sobre todo en ambientes populares).

Por sus raíces comunistas, hubiera podido apoyar esta estrategia de compromiso que se vale de la realidad como única fuente de inspiración. Pero esta realidad queda falsificada por el discurso oficial franquista:

Como concepción total de la realidad, el franquismo al día siguiente de su victoria plantea una política cultural basada en la falsificación del lenguaje y de la historia, el secuestro de la memoria de la España vencida u ortodoxa, el monopolio factual de todo aparato de creación de conciencia y el uso de la censura previa por si se le escapaba el control estructural de los medios de reproducción (Vázquez Montalbán, 2001b: 61).

Resultaba pues imprescindible "recuperar" una identidad "real" a partir de la ya conocida fase del realismo crítico fundamentado en un principio de ruptura. Una de las características de esta nueva forma de escritura es el uso recurrente de la ironía totalmente ausente en las generaciones realistas anteriores que introduce una distanciación saludable.

El realismo crítico es para Vázquez Montalbán una forma de ruptura que redefine la función del escritor frente a la historia y la literatura. Esta perspectiva supone la recuperación de la memoria auténtica que la "ideología dominante” deformó. Ya se puede entender que la ruptura es sobre todo 
ideológica, aunque tiene subcomponentes variados (lenguaje, discurso, género, estilo, etc.). Conviene subrayar que los mecanismos de esta estética de la ruptura no son fácilmente perceptibles.

En la novela, la ruptura aparece con mayor intensidad a partir de los años setenta. Con la serie Carvalho se abre el camino hacia un nuevo discurso fundamentado en la desconstrucción paulatina de la estructura de la novela. Es importante notar que la novela Tatuaje coincide con un movimiento de cambio general en España y la esperanza generalizada de un porvenir mejor. Pero de pronto desaparece este optimismo, lo que posiblemente obliga a Manuel Vázquez Montalbán a la formación de una nueva poética articulada por el concepto de crónica del desencanto. En ésta, permanece el personaje del detective con cierta evolución de la materia.

La ciudad que sigue representando el lugar de la investigación conoce ya muchas transformaciones. El escritor tiene pues que pintar esta realidad sin caer ni en los defectos del realismo anterior ni en la esclerosis del género que creó. Su postura consiste en una modificación de la forma o de la naturaleza de las novelas que en algunos casos dejan de ser novelas negras para volverse novelas de memoria. Esta evolución se hace a través de diversas propuestas estructurales que organizan las obras pero también a través de elementos formales que balizan una escritura esencialmente poética. Concretamente, la estructura de la novela evocada más arriba abandona ya la linealidad de la investigación para una composición en forma de espiral cuyos círculos concéntricos, al estrecharse sucesivamente en el espacio material y textual, materializa las aspiraciones del personaje principal. Resulta claro que este cambio de perspectiva rompe con los presupuestos de una novela criminal para centrar la atención en la víctima y el detective. Se trata pues de la afirmación de una voluntad de ruptura y de reivindicación.

En la poesía, la estética de la ruptura se nota fundamentalmente a través del ritmo. Se puede vislumbrar un rechazo de las formas tradicionales isométricas a favor del verso libre a veces con violentas rupturas rítmicas. Se caracterizan por la yuxtaposición de frases secuenciales bruscamente sincopadas que dan una impresión de discontinuidad a un discurso prácticamente sin puntuación y donde predomina el collage. El poema que sigue, "Paseo por una ciudad", presenta una perfecta ilustración del mecanismo (Vázquez Montalbán, 1985: 250): 


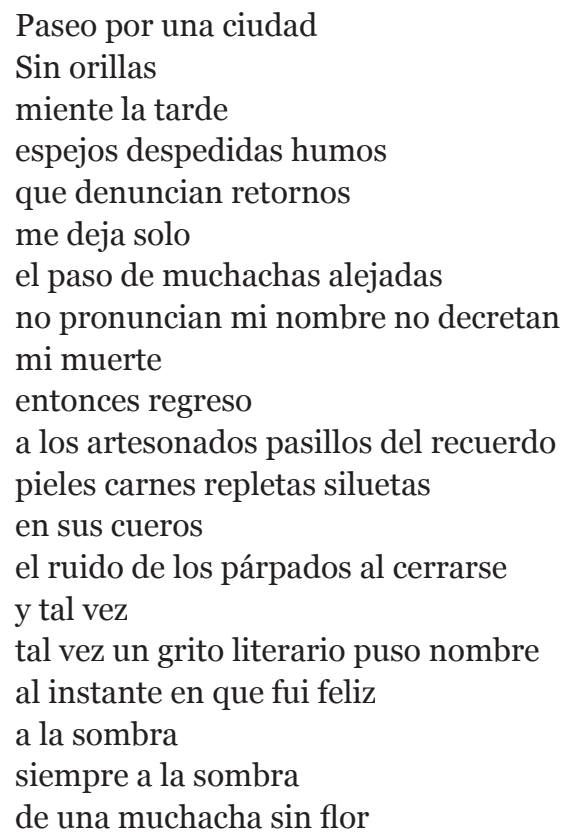

Aquí la fragmentación de la lectura queda reforzada por una distribución gráfica que genera rupturas y desfases en un texto cuya armonía visual y fónica parece perjudicada por temerarios encabalgamientos. Montalbán expresa así el poder de desmitificación del lenguaje poético en un mundo en constante disfunción. Es una forma de "música nueva" que se encarga del poder de protesta.

La obra de Montalbán presenta pues un mundo en constante renovación en oposición a toda forma de conformismo genérico exuberante integra la evolución de las sociedades urbanas. Esta ruptura supone una nueva aproximación mucho más lúdica a la realidad y tiene por objeto la conservación de la vitalidad de una escritura abierta a toda forma de comunicación y de cultura. Esta renovación rupturista resalta el carácter de un escritor atento a las mutaciones de su época edificando un nuevo espacio de lectura articulado por la escritura de "la novela urbana". Una novela que representa la ciudad como el espacio de la memoria, de la historia y de la nostalgia, un espacio caracterizado por la magia de una libre de todas las restricciones genéricas, de los anatemas y los yugos ideológicos. 


\section{La personificación de la ciudad}

La lectura de su obra evidencia las relaciones casi pasionales que tiene con Barcelona. Dichas relaciones muchas veces se fundamentan en la representación corporal de la ciudad percibida como una mujer: "Las ciudades son siempre mujeres". La aproximación a la ciudad se asemeja pues a la de una persona con todas las implicancias que supone. Así, observando la ciudad de Barcelona, el personaje Carvalho imagina un espacio dotado de implacables facultades mentales: "contemplaba una ciudad más dura, más vieja, más cínica inasequible para la esperanza de ninguna juventud presente $o$ futura" (Vázquez Montalbán, 2007a: 34).

Es importante subrayar la rareza de la observación que precede. La visión que prevalece es la de un ser maltratado por la vida y que intenta preservar sus encantos en decadencia: "La ciudad se había hecho la cirugía estética y de su rostro han desaparecido importantes arrugas de su pasado" (Vázquez Montalbán, 2002: 12).

El espacio geográfico se sectoriza en partes del cuerpo femenino. Se presenta la sierra de Collserola "como una caballera situada en los límites de Barcelona”, el Barrio Chino "corazón maligno de la ciudad” (Vázquez Montalbán, 2005a: 106) es también un vientre abierto, "tripas en sus rescoldos de prostitución barata” (Vázquez Montalbán, 2001c: 85), una imagen que se repite en el poemario Una educación sentimental. Esta parte de la ciudad herida y humillada suscita otra imagen anatómica insistente en la serie Carvalho, la de "las ingles" ligada a la de "las viejas carnes" (Vázquez Montalbán, 2007a: 29).

Barcelona es pues una presencia carnal que se deteriora con el tiempo. Pero también un ser que se apuñala con extraños instrumentos: "la piqueta abría espacios higiénicos en las viejas carnes" (Montalbán, 2005b: 44). Muchas imágenes de la mujer se superponen así en la lectura con muy pocos recursos a la idealización. La tendencia a presentar la ciudad "amada" como una vieja o una prostituta de poca monta impide de golpe el procedimiento sin por ello olvidar la ternura y la compasión. La ciudad es además una presencia física que seduce. Es también la perpetua compañera cuyo cuerpo padece ahora heridas y brutalidad y que es por consiguiente causa del sufrimiento del ciudadano: "le dolía cada violación de su paisaje infantil” (Vázquez Montalbán, 2005c: 59). 
Esta relación violenta que supone la apropiación del espacio "corporal” de la ciudad hace de la misma un objeto de sadismo: "en la metamorfosis de mi Barcelona había como un ejercicio de sadismo implacable” (Montalbán, 2007a: 132).

El cuerpo que se muere con sus muertos obliga al personaje montalbaniano y a Manuel Vázquez Montalbán a tomar conciencia de su propia mutación (Vázquez Montalbán, 2004: 115). Se siente despojado de su memoria y obligado a una forma de impotencia y parálisis que el morón loco de El estrangulador traduce con palabras que reflejan sus relaciones con la "ciudad de la memoria”. Dicha ciudad es, en sus barrios pobres, como una prostituta calva y sin dientes que ya no tiene sitio para su oficio (Vázquez Montalbán, 2005d: 193). Semejante configuración puede explicar la búsqueda, por Alberto Cerrato, de un refugio en la ciudad de su memoria que representa simbólicamente en los rasgos de Alma pero como lo sobreentiende el nombre, la ciudad pierde a través de ella parte de su corporeidad para reducirse a una simple fantasía personal, las tetas desiguales de la muchacha dorada. El estrangulador que vuelve a ser un adolescente, luego un niño retrocede en el tiempo y desea regresar a la placenta intrauterina. La ciudad se vuelve pues el vientre de una madre. Pasamos del vientre abierto a un sitio protector y cerrado. La toma de conciencia del fin engendra el comienzo como lo subraya Eliot.

La función reproductora de la ciudad de los origenes, origen de la vida aparece de nuevo aquí ya que "las ciudades abrigan como las patrias o los recuerdos” (Vázquez Montalbán, 2007b: 34). No se realiza sino haciendo coincidir con subterfugios intelectuales la memoria y el deseo de plenitud, aunque muchas veces la realidad obstaculiza esta aspiración. La ciudad se presenta así en su ambivalencia: ciudad de los orígenes que también es carnal y ciudad conceptual del conocimiento. Esta ambivalencia origina las reflexiones, las emociones y a veces las tensiones que observamos en la serie Carvalho.

Sin embargo, la personificación de Barcelona amplifica esta percepción carnal. En la poesía de Montalbán predomina la dimensión conceptual. Por eso en muy raras ocasiones encontramos un proceso de personificación de la ciudad. De ahí que aparece más bien como una entidad abstracta de tanto haber sido interiorizada e intelectualizada. La tensión evocada anteriormente se vuelve una angustia ontológica desconectada de los referentes circunstanciales o personal que pasaron por el filtro de la simbolización. 
El enfoque es de algún modo inverso. El léxico del espacio geográfico urbano material sirve para materializar o concretizar sentimientos, fobias y aspiraciones ya que la poesía es intrínsecamente "un alma inaugurando una forma" (Bachelard, 2012: 16).

La personificación de Barcelona desempeña pues un papel fundamental en la restitución de las ideas de Manuel Vázquez Montalbán tanto en la poesía como en la novela. A modo de conclusión, la representación de Barcelona en su obra obedece a la trayectoria ideológica y literaria del autor. Una trayectoria dictada por el contexto social, político y cultural de la España posfranquista. La postura rupturista del autor en adecuación con los cambios políticos que conoce el país en aquel momento define una escritura original de la Barcelona de su infancia. La personificación de la ciudad no solo materializa esta ruptura estética e ideológica, sino que representa la más viva manifestación de su afecto a su ciudad natal.

\section{Referencias}

Aranda, Q. (1995). Què pensa Manuel Vázquez Montalbán. Barcelona: Dèria. Bachelard, G. (2012). La poétique de l'espace. Paris: PUF.

Mitterand, H. (1980). Le lieu et le sens: l'espace parisien dans Ferragus de Balzac. En Le discours du roman (pp. 189-212). Paris: PUF.

Tadié, J. Y. (1994). Le récit Poétique. Paris: Galimard.

Tyras, G. (1985). Eéléments pour une biographie de Manuel Vázquez Montalbán. En Tigre 2 (pp. 219-223). Grenoble: S.E.I.I.A.

Vázquez Montalbán, M. (1985). A la sombra de una muchacha sin flor. Madrid: Editorial Laia.

- (1997). El escriba sentado. Barcelona: Crítica. . (2001a). Una educación sentimental. Madrid: Cátedra. . (2001b). La literatura en la construcción de la ciudad democrática. Madrid: Literatura Random House.

. (2001c). Ars amandi. Madrid: Bartleyby. . (2002). Sabotaje olímpico. Barcelona: Planeta. . (2004). Le désir de mémoire. Paris: Renaissance du Livre. - (2005a). El pianista. Madrid: Literatura Radom House. . (2005b) El hermano pequeño. Barcelona: Planeta. . (2005c). Los mares del sur. Barcelona: Planeta. . (2005d). El estrangulador. Madrid: Debolsillo. - (2007a). El laberinto griego. Barcelona: Planeta. . (2007b). Asesinato en el comité central. Barcelona: Planeta. 